\title{
CORRIGENDUM
}

\section{Size-specific catalytic activity of platinum clusters enhances oxygen reduction reactions}

Kimihisa Yamamoto, Takane Imaoka, Wang-Jae Chun, Osamu Enoki, Hideaki Katoh, Masahiro Takenaga \& Atsunori Sonoi

Nature Chemistry 1, 397-402 (2009); published online 20 July 2009; corrected after print 23 August 2010.

In the version of this Article originally published, the descriptions about data analysis of the electrocatalysis in the Methods section were incorrect; the corrected section is shown below. This has been corrected in the HTML and PDF versions of the Article.

$C_{\mathrm{O}}$ is the concentration of $\mathrm{O}_{2}$ in the electrolyte solution under pure $\mathrm{O}_{2}$ at atmospheric pressure $\left(1.2 \times 10^{-6} \mathrm{~mol} \mathrm{~cm}^{-3}\right), D_{\mathrm{O}}$ is the diffusion coefficient of $\mathrm{O}_{2}\left(2.0 \times 10^{-5} \mathrm{~cm}^{2} \mathrm{~s}^{-1}\right), \omega$ is the electrode rotation rate $\left(\mathrm{rad} \mathrm{s}^{-1}\right)$, and $v$ is the kinematic viscosity of water $\left(1.0 \times 10^{-2} \mathrm{~cm}^{2} \mathrm{~s}^{-1}\right)$; the physical constants are from ref. 41.

41. Ye, H., Crooks, J. A. \& Crooks, R. M. Effect of particle size on the kinetics of the electrocatalytic oxygen reduction reaction catalyzed by Pt dendrimerencapsulated nanoparticles. Langmuir 23, 11901-11906 (2007). 